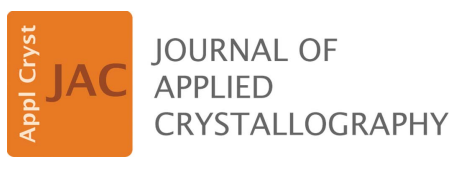

ISSN 1600-5767

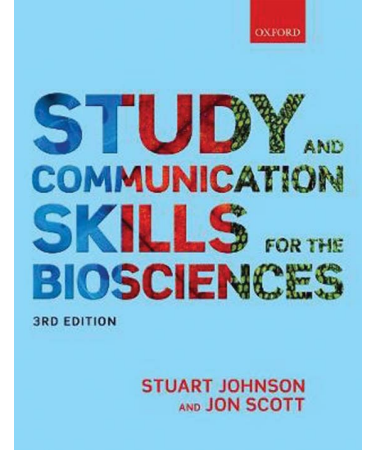

(C) 2019 International Union of Crystallography

\section{Study and Communication Skills for the Biosciences, 3rd edition. By Stuart Johnson and Jon Scott. Oxford University Press, 2019. Pp. 262. Price (paperback) GBP 24.99. ISBN 978-0-19-879146-1.}

\author{
John R. Helliwell*
}

Department of Chemistry, University of Manchester, Manchester M13 9PL, UK. *Correspondence e-mail: john.helliwell@manchester.ac.uk

One of the universal roles of an educator is to convey to students the necessary study and communication skills, whether in science or in arts and humanities. This book addresses these key skills as a manual for students through their course and as preparation to enhance their attractiveness to employers. The book is stated to be for bioscientists. The examples are from bioscience, such as measuring the leap distances of a laboratory population of locusts or migratory behaviours of geese, but are readily understandable for all. I liked this book and indeed wished I had had such a book when I was a student. I will explain why I liked it, and it is not surprising to me that it has reached a third edition. I will pick out some interesting oddities, though, that the book has in my view.

There are 15 chapters:

1. Why are study and communication skills important?

2. Using feedback

3. Making the most of lectures

4. Working with different information sources

5. Academic integrity and avoiding plagiarism

6. Choosing the right writing style

7. Writing essays

8. Writing practical and project reports

9. Working in tutorials and groups

10. Preparing scientific presentations

11. Delivering scientific presentations

12. Creating academic posters

13. Getting the most out of revision

14. Getting the most out of exams

15. Making yourself employable

There is a subject index, albeit rather short ( $1 \frac{1}{4}$ pages).

Each chapter has an introduction and a chapter summary at the end.

Chapter 1 is a motivational chapter for students, and Chapter 2 is about feedback. In Chapter 3 the book gets into its stride. It introduced me to the 'flipped lecture' for teaching, where students prepare by watching or reading a short introduction and the 'lecture' time is given over to open discussion. This sounds like the Royal Society of Chemistry Faraday Discussion, a very stimulating method for carefully sharing research and then having an abundance of time to discuss each presentation. Will undergraduate students be as conscientious, though, as a professional researcher in preparing for such a lecture? This issue reminded me that a lecture is an amazingly effective way of covering all the bases, especially for the unprepared or less than conscientious student. The authors describe 'additional reading', which is good but glosses over the issue of making clear to students what is not going to be in the exam, and students can get anxious if there is 'too much' additional reading. Chapter 3 concludes with a nice chapter summary, and indeed it has a nice introduction. The authors are clearly following the careful dictum of 'Tell them what you are going to tell them, then tell them and finally tell them what you have told them'! 
In Chapter 4, page 35, I noticed what I am going to call an oddity. In describing the structure of research papers the authors state these are organized with Title, Abstract, Introduction, Methods, Results and Discussion. But no Conclusions. This surely cannot be correct? I made several checks and indeed it varies between journals. But in this book such a layout is again described on pages $50-51$ and page 121, Chapter 8, and likewise on page 135. However in Chapter 11, page 181, and on page 192 in Chapter 12 a conclusion section is included. It seems that students will have somewhat inconsistent advice in this book on this aspect. The section of this chapter on searching the literature is very good and usefully specific, as is the explanation of critically evaluating a research paper.

Chapter 5 is entitled Academic integrity and avoiding plagiarism. Page 63 explains well how students working in pairs can write up their laboratory experiments independently rather than having very similar write ups. Likewise the subject of spotting plagiarism in student essays is neatly covered within the authors' seven examples, only two of which are not plagiarized. The practical approach to essay-tasks time lining in Fig. 5.4 will guide the student to good planning and help them avoid being rushed and maybe lapsing into plagiarism.

Chapter 6, Choosing the right writing style, is very good, including useful clarifications on punctuation. Chapter 7 on writing essays is also very good, recognizing that different people have different essay research preparation and writing styles. Chapter 8 is on Writing practical and project reports. It seems odd to me that there is no mention of health and safety assessments before starting the experiment, and no mention made in writing it up. The authors do point out on page 127 that in the case of human subjects prior ethics approval is needed, although they do not mention a similar requirement with animals. Pages 137-138 are an especially nice description of how to properly draw graphs of data. Chapter 9 on Working in tutorials and groups is very good, although it mentions that a tutorial group might involve up to 20 students, which seems to me far too large - up to six students is more typical, at least in physics and chemistry departments. Since team-working skills of graduates are highly valued by employers, this chapter is especially important.

Chapter 10 on Preparing scientific presentations is also good. However, it does contain what I consider a second, more major, oddity. On page 157 the text states 'Science is, by its very nature, objective. That is to say, observations made during scientific research should be impartial, and not influenced by personal feelings or opinions. So it follows then that a scientific presentation should also be objective.' In my opinion this section of the book should have gone on to make clear that, as a critical study skill, experimental science realizes objectivity by sharing with readers the underpinning measured data of the research along with the scientist's narrative, which by its nature is an interpretation. Theoretical science can reach objectivity by its predictions, which can then be tested against measurements.

Chapter 11 is on Delivering scientific presentations. Table 11.2 is an excellent summary of the advantages and disadvantages of various visual aids. Neither this chapter nor Chapter 10 emphasizes that the number of slides prepared should not exceed approximately one per minute in a presentation, as a guideline. The authors also do not explain to the student that every piece of information on a slide should be explained, otherwise why is it there? The optimal choice of text and background should be emphasized: black text on a white background works well, as does white text on a blue background. Likewise colour blindness must be allowed for, and therefore red and green colours in the same slide should be avoided. Also, mention could be made that sans-serif fonts are easier to read by dyslexic people. But the authors do clearly say that it is good to practice a presentation which allows one to check various details. Chapter 12 is on Creating academic posters. It starts well with the authors' seven-step guidelines. They then give examples with far too much text versus the number of images for my liking.

Chapter 13 is on Getting the most out of revision. This chapter is very good. It covers various situations, including the one where there is no past exam paper to provide revision questions: the authors recommend that the students themselves create a question bank. Chapter 14 is on Getting the most out of exams. The first parts of this should have gone into the previous chapter, for example last-minute revision. I also disagree with the authors' advice on how a student should spend their time the night before an exam. They describe an evening of some preparation, whereas I would recommend relaxing, thereby giving the mind and body a break from the revision marathon, as the authors call it overall. This chapter does have various useful tips for when the student is in the exam itself, including answering as well as possible the different types of questions.

Chapter 15 is on Making yourself employable. This is a very pragmatic chapter with many tips and guidelines for final-year students approaching their next steps after graduation. It does describe going into postgraduate study, masters or $\mathrm{PhD}$, but focuses on other employers. In deciding what to do next the need for the student to 'know thyself' comes across firmly.

In terms of production quality of the book by OUP I do have some criticisms. Fig. 4.1 on page 38 is too small and congested with details; putting it on its side to use the full page might help, but it is basically a difficult figure and should be improved by the authors. Fig. 5.11, page 80, is also way too small. Pages 45-47 have several figures which I found difficult to read owing to use of italics in a very thin font on a pale-blue background. Page 58 is a nice chapter summary but the typeface is very small. Chapters 8 and 11 both have long introductions, and with their very small typeface these introductions are not an easy read.

In describing the third edition of the book the publisher says 'New to this edition, the book now includes discussion of how best to use recorded lectures in learning and revision, and how to get the most out of flipped classrooms and interactive lectures. The chapter on employability has new content on technological change in the workplace, how to perform well in a video interview, and how best to use online networks for career advancement. A new section also explores how to 


\section{book reviews}

critically review a research paper. A new learning feature, 'Try this for yourself', shows how you can apply the book's principles to your own life and studies.' These are good topics to see included in such a book, and I agree that they are very good additions to make this third edition up to date.

Overall this is a very good book and I recommend it to students across many subjects, not only biosciences, because as I mentioned the examples from biosciences are readily digestible. There are a few places where I think the text could be improved, as I described above. The production quality has the various lapses that I also mentioned. There is an online resource at http://www.oup.com/uk/johnson3e/ which is for 'registered adopters'. This has 'the figures and tables of data from the book, being ready to be downloaded'. The web site also states that the 'student resources include tests and quizzes'. These web resources are good to see, too. 